\title{
Lectura latinoamericana de los Ejercicios Espirituales de san Ignacio*
}

\author{
Ignacio Ellacuría \\ Centro de Reflexión Teológica, \\ San Salvador, El Salvador.
}

1. Los Ejercicios como experiencia teologal y principio pastoral en la realidad eclesial latinoamericana

1.1. Necesidad cristiana de latinoamericanizar la teología y la pastoral en América Latina

- Aunque en principio puede parecer obvio la necesidad de una latinoamericanización de la pastoral y de la teologia en América Latina, el quedarse en esta obviedad tiene fatales consecuencias para la teología y para la pastoral:

+ los que entienden la latinoamericanización como una simple aplicación de principios universales - y esto es lo que les parece obvio- trivializan el problema y no dan cuenta adecuada de la historización de la salvación,

+ los que la entienden como algo que debe surgir totalmente aqui y ahora, en dependencia absoluta de la realidad socio-econónica y cultural, no dan cuenta adecuada del carácter propio de la salvación cristiana.

- En septiembre de 1974 la UCA ofrecio un curso sobre los Ejercicios Espiritunles de an Ignacio. E P. Ignacio Ellacurra abordo el tema de la historizeción de los ejercicios desde el tercer mundo y especificamente desde Amkrica Latine Siempre uvo el deseo de redactar y publicar las ocho conferencias que impertió en el curro, pero no le fue posible. Ofrecemos ahora los resúmenes de cada una de las conferencias tal como el mismo los elaboro. 
- Tanto la historia de la teología como la historia de la pastoral nos muestran profundas diferencias a pesar de continuados intentos impositivos que buscan la unidad a través de una uniformidad coercitiva:

+ el análisis de las condiciones ideológicas de la unifornidad puede poner de manifiesto las raíces no cristianas de muchos planteamientos teológicos y comportamientos pastorales,

+ la presencia no sólo en el Antiguo sino en el Nuevo Testamento de teologias distintas prueba la necesidad y las condiciones de la historicidad de la salvación y de sus instrumentos interpretativos y práxicos:

- no es que justifique cualquier pluralismo y menos cualquier relativismo, porque la unidad del principio inspirador rechaza las mundanizaciones del mensaje.

0 pero sí muestra la necesidad de responder históricamente a la interpretación histórica de la fe.

+ El Vaticano Il sostiene que "es necesario que en cada territorio sociocultural se promueva aquella consideración teológica que someta a nueva investigación, a la luz de la tradición de la Iglesia universal, los hechos y las palabras reveladas por Dios, consignadas en la Sagrada Escriura y explicadas por los padres y el magisterio de la Iglesia ( $A G, 22 \mathrm{~b})$.

+ Medellín muestra en concreto la posibilidad y la necesidad de esta historización de la leología y de la pastoral por lo que toca a América Latina, pero lo ocurrido desde Medellín nos muestra las grandes dificulades de este proceso.

- Esta latinoamericanización de la teología y la pastoral requiere la vivencia profunda y la recta interpretación tanto de la salvación cristiana como de la realidad historica:

+ la salvación cristiana requiere una auténtica vivencia y una recta interpretación, to cual no se consigue ni con repeticiones doctrinales ni con liturgias abstractas,

+ lo mismo cabe decir de la realidad latinoamericana, que no es captable, sino en la praxis de su proceso histórico.

- El problema fundamental que enfrentan tanto la teología como la pastoral latinoamericana es el de cómo entender y cómo realizar la historia de la salvación en la propia situación latinoamericana. Esta formulación, como las anteriores, puede parecer obvia, pero pone en juego la cuestión fundamental de la relación de la historia de la salvación con la salvación en (de) la historia: 
+ no se trata de una cuestión teórica, sino que es la realidad histórica de un pueblo que se entiende a sí mismo en proceso de realización histórica y que, cristiana y latinoamericanamente, no puede disociar la salvación de la historia:

- la disyuntiva entre dimensión personal y dimensión histórica es falsa tanto por parte de los que se refugian en lo personal como por quienes se refugian en lo histórico,

- hay sí un problema real de ver cómo conciliar en la praxis y en la vivencia los fueros de lo personal y las necesidades de lo histórico.

+ El encontrar a Dios en la realización histórica es problema esencial de la teología, de la pastoral y de la espiritualidad, que se requieren hoy en América Latina:

O no es tanto problema de conciliación de la fe con la ciencia o de la moralidad con la felicidad, sino de conciliación del mensaje de salvación con la praxis histórica,

- el redescubrimiento de Dios en la praxis histórica cuyo sujeto es un sujeto colectivo, es tema fundamental de la teología y es pauta determinante de la pastoral y de la espiritualidad.

- Sólo en una esencial referencia a la historia de la salvación, con su momento decisivo en el Jesús histórico, se ve la posibilidad cierta de resolver ese problema fundamental:

+ en el Jesús histórico se da la máxima presencia de Dios en la historia y el verdadero dinamismo para perpetuar esa presencia.

\subsection{Los Ejercicios de san Ignacio como lugar teológico de historización}

- Los Ejercicios de San Ignacio, al pretender el encuentro personal de la voluntad de Dios, son ya principio de historización:

+ no sólo participan de la general historización que implica la escucha viva de la palabra de Dios:

- no reducen la palabra de Dios a un texto fijo y ahistorico del que se sacan conclusiones lógicas,

- preparan su recepción viva desde la propia situación.

+ También historizan esa palabra de Dios en cuanto recurren a signos históricos, personales y circunstanciales, para poderla descubrir concretamente:

0 es cada uno quien debe ver en su propia historia una de las bases esenciales del encuentro de la verdad y de la voluntad de Dios, 
0 se requiere un esfuerzo de discreción y discemimiento, pues la sefal no es unívoca, sino que necesita interpretación.

+ También la historizan en cuanto son un mélodo para encontrar una voluntad de Dios no deducible de principios universales (cf. Karl Rahner. "Die Logik der existentiellen Erkenntnis bei Ignatius von Loyola", en Das Dynamische in der Kirche, 1958, pp. 74-148; hay traducción castellana):

- son asf un elemento de dinamización de la Iglesia en cuanto avanzan en la comprensión y en la práctica lo que es la acción histórica de Dios,

- hay algo esencial para la vida, que todavía no ha sido dicho por Dios y que surge como algo nuevo y futuro.

+ Son plenamente activos en cuanto se apoyan en una elección y se dirigen a una praxis:

- no son puramente contemplativos ni se quedan en el campo de la pura pasividad, sino que van a la reforma activa y a la transformación,

0 pretenden realizar el cumplimiento de una misión en el mundo.

- Los Ejercicios de san Ignacio tienen el peligro de deshistorizar la salvación en cuanto pueden reducirse a una problemática puramente individual sin referencia al sujeto histórico que es el pueblo de Dios; sin embargo, este peligro es superable:

+ el que se orienten originariamente a cada individuo y en térninos a veces de salvación del alma puede hacer pensar que su orientación fundamental y sus mecanismos no permiten la historizacion:

- subrayan más lo individual en la realización personal, pero no excluyen lo histórico más allá de lo biográfico,

- en lo que tienen de planteamientos estrictamente personales aportan uno de los elementos importantes de lo histórico.

+ El que san Ignacio mismo haya visto la posibilidad de dar cuerpo público al espiritu de los Ejercicios en la Companía de Jesús es prueba de la capacidad de historización que tienen:

- la Companía de Jesús es una institución histórica que pretende una eficacia histórica a través de medios históricos, y esto como encamación y propagación del mensaje cristiano,

- los Ejercicios de san Ignacio sirven también para tomar decisiones por parte de muchos sobre temas que afectan a muchos y que tienen visibilidad histórica. 
- Los Ejercicios de san Ignacio utilizan fundamentalmente un método histórico, que es teológicamente muy operativo para la historización de la fe y de la praxis cristiana:

+ intentan poner la propia historia como lugar hermenéutico de lo que uno es y de lo que es para uno la voluntad de Dios:

- apuntan asi a una teología apoyada en la realidad de lo histórico en su triple dimensión de pasado, presente y futuro,

- propician para la leología los mismos pasos fundamentales que para la fe.

+ Hacen de lo histórico la parte esencial de la estructura del encuentro crisliano de Dios,

- sólo el Principio y fundamento y la Contemplación para alcanzar amor parecen hacer excepción a la primacía de lo histórico, pero sólo aparentemente,

- en el resto de los Ejercicios de san Ignacio lo histórico, como historia de salvación y salvación en la historia, es lo más esencial de su planteamiento.

+ La primacía del Jesús histórico en la estructura de los Ejercicios de san Ignacio es tan evidente que ya por esto se constituyen en un método aptísimo de historización cristiana y de teología latinoamericana:

- La primacía es tal que el Cristo de la fe pasa a un segundo plano, pues su aparición no tiene sentido, si no es tras el recorrido efectivo de lo que es la Segunda semana, en la que está lo más típicamente ignaciano,

- la interpretación que se hace del Jesús histơrico supone una auténtica conceptuación histórica en términos de Siervo de Yahvé, que es esencial para la teología latinoamericana:

- los Ejercicios de san Ignacio no son puramente una narración, sino que tienen su propio logos histórico,

* y este logos histórico nos presenta un Jesús de gran significado para el problema de la teología y de la pastoral latinoamericana.

+ Todo el tema de la discreción de espirius es también esencial al método histórico, sobre todo como requisito para encontrar la verdadera praxis cristiana, no sólo por lo que tiene de discermimiento, sino porque ese discernimiento debe encontrar en la realidad histórica el modo de seguimiento del Jesús histórico, siendo este seguimiento la clave esencial de la teologia y de la praxis cristiana en América Latina. 


\section{El esquema formal del Principio y fundamento y la necesaria superación historica de su ambiguo formalismo}

\subsection{EI peligro de deshistorización en el Principio y fundamento}

- El Principio y fundamento puede presentarse de tal modo que suponga un previo conocimiento racional de lo que es Dios con independencia de lodo proceso histórico:

+ se supondría que el hombre usando un tipo de razón, predominantemente naturalista y abstracta, alcanzaria la naturaleza de Dios y aun su caracter de creador:

- este camino de conocimiento de Dios tiene sus raíces en algunos planteamientos de la Escritura, en el magisterio y en algunas formas clásicas de teología,

- codo ello plantea el difícil problema de la razón natural y de la conexión del conocimiento natural de Dios y del conocimiento revelado.

+ Aun dejando de lado la discusión de la razón natural, es claro que el Dios cristiano no es accesible al margen de la historia:

- cualquiera sea la posiblidad de alcanzar a Dios por la razón natural, es la razón histórica, el logos histórico, el instrumento de la captación más plena de Dios:

* lo que entendemos por naturaleza física puede dar algún acceso a Dios, pero sólo enmarcado en lo que es la verdad del proceso histórico tolal,

- es en la historia donde la naturaleza cobra su sentido y su totalidad, asf como la historia no tiene su realidad, sino en referencia a la naturaleza,

- es más pensable el don de Dios a los hombres en términos de historia que en términos de naturaleza, de modo que la conexión diferenciada no es naturaleza-gracia, sino historia de la salvación-salvación de la historia:

- aunque la naturaleza en sentido clásico incluiría de algún modo lo histórico-humano, en el fondo, subordina lo histórico a lo natural,

- es la historia el medio de conexión entre lo más propio de Dios y lo más propio del hombre.

- El Principio y fundamento puede presentarse de tal modo que suponga un previo conocimiento de lo que el hombre debe hacer para encontrar a Dios, de suerte que la presencia de Jesús sólo aportaría fuerzas nuevas para hacer lo que ya se sabía: 
+ habrla una ley natural correspondiente a la razón natural que determinaría fijamente los modos de encuentro con Dios y los modos de su rechazo:

o hay, por lo pronto, el peligro de que esos modos racionales de encuentro sean reflejos ideológicos de una situación, con lo que la razón natural que los expresa sería una razón histórica, pero acríica,

- la mejor expresión de ese encuentro serfa la ley, que expresaría de por sí los contenidos salvíficos:

* se daría una preferencia a la ley sobre la fe, a los contenidos legales sobre la relación personal y el seguimiento,

* esta ley sería fija, no sólo en su dirección y en su formalidad, sino Lambién en sus contenidos concretos.

+ No se reconocería la ruptura cristiana y, consiguientemente, el escándalo y la locura que irrumpen definitivamente en el principio y fundamento que es el Jesús histórico:

- se preferirá la prudencia, el buen sentido, el ser correcto, etc., a la locura y el escándalo del Dios que se entrega a los hombres por caminos insospechados,

- surge así un principio y fundamento que es una persona histórica y que pone en lo histórico la salvación de Dios.

\section{Para una lectura historizada del Principio y fundamento}

- Si el Principio y fundamento se presenta como un problema del hombre y no como una solución, entonces desaparecen sus peligros racionalizantes que ponen en quiebra la posibilidad misma de historización:

+ no es una solución, porque, de lo contrario, carecerían de sentido revelante todo el resto de los Ejercicios,

+ es, ante todo, un problema tanto de orden térico como de orden práxico y en ambos aspectos propone unas pistas formales y unas fuerzas de dirección, cuya confirmación estará en la historia de la salvación y cuya realización estará en la salvación de la historia:

- el problema de orden teórico está en que hay que preguntarse lo que el hombre es y lo que el hombre tiene que hacer para ser, si es que ha de surgir seriamente el problema de Dios y su respuesta,

- el problema de orden praxico está en que la actitud totalmente cristiana no se encuentra, sino en términos de maximalidad,

+ como consecuencia práctica, debe sacarse que el Principio y fundamento no es pauta de la vida, pues de lo contrario se convertirla la vida en un ejercicio de racionalismo y de pelagianismo estoico. 
- En el Principio y fundomento, a pesar de su apariencia racionalista y voluntarista, hay, sin duda, una presencia de dinamismos cristianos:

+ san Ignacio lo aflade a los Ejercicios posteriormente a la estructura esencial de éstos, lo cual significa que no lo ve en contraposición a ellos y que debe ser interpretado introductoria, pero subordinadamente a lo que es el núcleo de los Ejercicios,

+ problemas como los de la creación y los de la salvación situan su interpretación en una línea de radicalidad cristiana, aunque la referencia a la historia no sea aquí tan explícita:

- podría verse aquí un tipo de presentación como el de Col 1, 15-20, pero con el mismo peligro de creer que a Dios se lo entiende de arriba a abajo y no al revés,

- es desde el Jesús histórico, Dios dentro de la historia, desde donde se puede entender la creación.

- La creación debe entenderse, por tanto, como principio de la historia de la salvación:

+ no se trata meramente de la aparición de una naturaleza sobre la que más tarde aparecerá la gracia, sino del inicio de un proceso libre y gratuito. por lanto histórico, cuya plenitud y verdad está en el futuro, de modo que éste no se conforma al origen, sino que el origen se entiende desde el futuro al que se proyecta y que todavía no contiene,

+ la creación es fundamentalmente relación al hombre y al hombre que tiene que actuar en la historia:

- el hombre es el sujeto del Principio y fundamento (el hombre es criado para...), y lodas las demás cosas entran en la creación al servicio de lo que es el hombre como sujeto de la historia de la salvación,

- no se trata de un hombre que sólo ha de recibir y contemplar, sino del hombre que ha de actuar.

— La libertad es punto esencial del ser del hombre y como tal es principio de historia:

+ para san Ignacio hay cosas dadas, pero hay el campo decisivo de "lo que es concedido a la libertad de nuestro libre albedrio", y es ahí donde va a darse el campo de lo típicamente cristiano,

+ la indiferencia no es lo cristiano, sino que es tan sólo condición para poder seguir el más de la exigencia cristiana; con todo la indiferencia es también un ejercicio de la libertad:

0 tal vez pueda reconocerse una libertas indiferentice, que no es propiamente ejercicio de libertad, sino posibilidad de ella, 
- la verdadera libertad estarfa en la posibilidad de ir más allá del “juicio y razon", movida por el amor y el seguimiento de Jesús.

- No puede darse por evidente a la alura del Principio y fundamento qué es alabar, hacer reverencia y servir a Dios nuestro Seffor, porque ni siquiera se conoce quién es ese Dios nuestro Seflor para los hombres:

+ son el resto de los Ejercicios lo que dirá en qué consiste ese servicio, porque en ellos se hace presente el revelador de Dios y el camino de vida,

+ incluso qué es la salvación del alma, que se presenta como el fin del hombre, es algo que queda por determinar.

- san Ignacio arranca también, como hoy también lo necesitamos, del deseo y la urgencia de la salvación.

- el problema que queda abierto es cómo el deseo de salvación personal se junta concretamente con la necesidad de la salvación histórica.

3. La concepción integral del pecado como punto de arranque para una interpretación cristiana de la liberación

3.1. La superación de la teología creacionista (desarrollista) en la teologia de la historia de la salvación

- San Ignacio acepta el marco de la creación pero como comienzo de una historia de la salvación que tiene como punto esencial el pecado:

+ el hecho es evidente por la existencia misma de la Primera semana y por el peso que en ella tiene la realidad del pecado.

+ cualquier interpretación de la realidad y dèl cristianismo que no tenga como punto esencial el pecado es una interpretación superficial y no ignaciana tanto de la realidad como del cristianismo:

- la realidad del pecado pone en claro lo que es la realidad de la creación y hace presente desde un principio un elemento de negatividad que es esencial a la realidad:

* Io negativo hecho real sólo es superable por una negacion real, que implica un momento de lucha,

- se plantea aś la historia en términos dialécticos, que son también esenciales al mensaje salvifico.

- El cristianismo, centrado en la significación del Jesús histárico, es ininteligible históricamente sin la presencia del pecado: 
- lo que fue históricamente la vida de Jesús es ininteligible sin una referencia inmediata al pecado tanto de las personas como al pecado objetivado y socializado (historizado) de las estructuras,

- la interpretación teológica de la muerte de Jesús carece de sentido sin referencia al pecado, al pecado de los hombres y al pecado del mundo.

- Las teologias que en la práctica son creacionistas anulan a la par el momento dialectico y el momento cristiano de la historia:

+ si el mundo no tiene en si un principio de mal, lo único que necesita es ir desarrollándose positivamente, con lo cual desasparece el esquema esencial de la interpretación cristiana: encamación-muerte-resurrección:

- recurrir de inmediato a una teologia del Verbo y saltar desde el Verbo al Cristo resucitado es un escamoteo de la historia y una negación docetista de Cristo,

- en el fondo, se trataría de una ideologización teológica, que mantiene el orden establecido y que no pone ruptura ninguna de la evolución naturalista:

* no se acepta el escándalo y la ruptara de la salvación en lo que es historia del hombre,

" una de las formas específicas de la aparición de la "gracia" es como superación del pecado.

+ Las teologías montadas sobre la historia de la salvación (como la de san Ignacio) siaian el momento creacionista en dependencia del momento histórico que pasa por la acción del hombre:

- esta acción del hombre es donde más aparece tanto la negación como la afirmación de Dios,

- aparece asi el pecado como algo que afecta intrínsecamente al hombre y a su historia, y que da razón del mal que afecta al mundo y que hay que hacerlo desaparecer.

- se pone así en relación intrínseca a Dios con el hombre en la mediación de la historia,

- se prepara así el encuentro de Dios en la acción histórica de los hombres.

\subsection{El esquema teologico del pecado en las meditaciones de san Ignacio}

- El pecado tiene una triple dimensión -pretérita, presente y escatológicaque lo constituye en esencialmente histórico: 
+ el pecado afecta históricamente a loda la creación e implica un determinado ejercicio de la libertad:

- el pecado de los ángeles indica hasta qué punto el pecado lo es de la creación misma, aunque implica un momento histórico de opción y de ejercicio de la libertad,

- ya en nuestra propia historia es una acción humana la que se objetiva y afecta a la humanidad (cuánta corrupción vino al género humano):

- biblicamente la teología del pecado es una respuesta a la presencia del mal en el mundo, y éste sigue siendo un principio hermenéutico de lo que hoy haya de malo en el mundo,

* Lambién aquí hay un momento de libertad personal, pero esta libertad origina una situación histórica que es, en alguna manera. pecado y hace pecadores (activa y pasivamente) a los hombres.

+ El pecado afecta históricamente al presente de los hombres, de suerte que hay un modo presencial del pecado:

- el pecado personal es personal (particular lo llama san Ignacio), pero no por eso está al margen de lo histórico-colectivo:

- precisamente, porque es personal va a implicar una dimensión personal en la historia de la salvación, y esta dimensión personal es esencial a la historia,

- sin embargo, es un pecado que condiciona la historia, pero que antes es condicionado por ella:

- puede hablarse hasta cierto punto de un pecado natural, aunque la Escritura le da un sentido histórico.

- pero ese pecado actúa y se visibiliza y realiza más o menos según las acciones personales de los particulares y su reflejo objetivo en lo histórico,

- el pecado personal, por serlo, necesita de una estricta conversión personal que no resulta pasivamente de un puro cambio de estructuras:

- la insistencia de san Ignacio en los exámenes prueba lo interesado que estaba por esta dimensión personal, así como su técnica de suscitar afectos personales muestra hasta qué punto no cree en una libertad pura,

- aun en esta dimensión personal la mayor gravedad está en la realización del pecado en cuanto que causa "mayor daflo" (Ejercicios Espirituales 37) a otra persona. 
+ El pecado afecta historicamente al futuro en cuanto tiene una dimensión escatológica:

- el pecado cobra su total sentido en función del futuro que configura:

- va cobrando más poder, se apodera más del mundo, y así se objetiva más y más,

- dificulta asl el futuro de Dios entre los hombres, el pleno advenimiento del reino de Dios,

- al pecado sigue la pena como resultado objetivo de lo que es el mismo:

- no siempre va unido el pecado con la totalidad de la pena que le es propia,

- por eso implica también una cierta pena impuesta

- Sólo desde la cruz de Jesús se ve qué es y qué hay que hacer con el pecado:

+ el pecado es, en definitiva, la crucifixión del Hijo, tal como se nos muestra en Jesís de Nazaret:

- es negación del Hijo, que queda abandonado por Dios en la cruz, y la negación del Hijo es resultado de la negación de la fraternidad entre los hombres y de la paternidad del Padre,

- pero no es una negación abstracta, sino que es la destrucción de un hombre concreto, que en su vida concreta estaba mostrando lo que es Dios como Padre:

- el pecado no es asf algo puramente deducible de lo que se ha planteado en el Principio y fundamento,

- es la negación de algo histórico y se realiza en la negación de algo histórico.

+ Solo por la cruz se da la revelación del pecado y superación:

- la cruz de Jesús es la negación que el mundo hace de Dios y es la negación que Dios hace del mundo; en ambos casos se trata de una negación histórica, aunque con un significado que supera la historia,

- puede hablarse de reconciliación, pero esta pasa por la negación y la lucha de la cruz tanto a nivel personal como a nivel histórico.

\section{La liberación del pecado}

- Lo que formalmente hace la salvación en la historia es liberarla del pecado medianle la comunicación de una nueva forma de vida, según el esquema muerte-resurrección: 
+ es en el pecado histórico donde coinciden el mal del mundo y la presencia o ausencia de Dios, de suerte que la acción respecto del pecado no separa lo "religioso" de lo "secular",

+ pero a lo que formalmente se dirige la acción salvifica es a lo que hay de pecado en el mal del mundo:

- esto no implica abandonar la realidad personal y social, sino que, al contrario, las radicaliza porque las sitúa en una dimensión absoluta,

- supone, además, que todo pecado configura al hombre y en alguna medida a la historia, pues los grandes males de la persona y de la sociedad se deben a lo que hay en el hombre de pecado y de negación de la vida que nos muestra Jesús:

- autodestrucción humana por falla del debido ser personal con culpa de uno o culpa de los demás,

* el mal hecho a los demás surge casi siempre de una actitud de pecado,

* específicamente el mal colectivo de la injusticia social es en sf mismo pecado (negación del reino), es causado por el pecado y no es salvado por la resistencia que hace el pecado.

- Es en lo histórico donde se descubren los pecados de los que el hombre debe ser liberado para alcanzar su condición de hijos de Dios:

+ no hay primariamente un catálogo de pecados, recogidos en la ley, sino una serie de valores fundamentales, expresados en la historia de la salvación, sobre todo en los profetas y en Jesús:

- estos valores deben realizarse personal y socialmente y su negación no exige sólo un perdón extrínseco, sino un deshacer real y un hacer nuevo,

- estos valores de la historia de la salvación no son arbitrarios, sino que tienen que ver con los valores fundamentales del hombre y con las actitudes fundarnentales de éste.

+ La tarea cristiana es la de liberar el pecado del mundo y la de construir el nuevo hombre y el nuevo mundo:

0 una vez determinados los pecados del mundo, la actitud cristiana es la de lucha contra el y contra quienes se aferran opresivamente a el; el inconformismo y la rebeldía son asi actitudes exigidas por el ser cristiano,

- es también la de construir un hombre nuevo en la construción de un mundo nuevo, que en la cruz de Cristo ve el camino de la resurrección y de la presencia del reino de Dios: 
* el comenzar desde el pecado no quita al cristiano su esperanza; tan sólo le da realismo,

* la dialéctica de anuncio-denuncia, destrucción-construcción, liberación-libertad es esencial al cristianismo.

4. El seguimiento histórico como pueblo de Dios del Jesús histórico hacia el Cristo que ha de venir

4.1. El carácter esencial del seguimiento en la estructura de los Ejercicios de san Ignacio

- Es en la Segunda semana donde san Ignacio da su interpretación clave del cristianismo:

+ los Ejercicios de san Ignacio, como la fe y la vida cristianas, son una totalidad que incluye unitariamente partes y aspectos distintos en permanente tensión:

- muestran en un proceso histórico, permanentemente repetido, el pecado, la vida de Jesús, la muerte, la resurrección, situados entre el Principio y fundamento o la Contemplación para alcanzar amor,

- estas partes no son sucesivas, aunque muestran un estricto orden histórico real, sino que se hacen mubuamente presentes y se condicionan entre sí:

- ya el mismo pecado se ve como pecado desde la cruz y no como pura violación de la ley o como mera falta y culpa moral,

- la vida de Jesús - y con mayor razón la muerte- es tal porque se desarrolla históricamente en un mundo de pecado.

- incluso la resurrección no invalida la vida de Jesús y no anula el enfrentamiento con el pecado,

- esta interacción mutua es de estricta tensión, de modo que la anulación de una de sus fuerzas llevarfa a la desfiguración de la unidad cristiana

+ Pero esa totalidad que son los Ejercicios de san Ignacio tienen su clave interpretativa en la disposición misma de la Segunda semana y en la teologia de sus meditaciones fundamentales:

- de hecho, la Segunda semana incluye los textos más originales de san Igracio,

- la Segurda semana expone el modo de vida "para " conseguir todo bo demás. 
- La Segunda semana está presentada en têrminos de seguimiento del Jesús historico, de modo que en este seguimiento aparece lo esencial de la vida cristiana:

+ al ser éste un hecho esencial a la estructura de los Ejercicios de san Ignacio, muestra a éstos no sólo como medulamente cristianos, sino además muy útiles para una teologla y una pastoral latinoamericanas,

+ san Ignacio apunta las características generales de este seguimiento:

- el seguimiento arranca de un llamamiento, de una vocación y no de una conclusión racional o de una previa experiencia religiosista,

- el seguimiento presupone ante todo una adhesión personal a la persona de Cristo en la presencia de su humanidad:

- no es porque se sabe ya de Cristo que se llega a la vida de Jesús, sino que es primariamente la vida de Jesús la que lleva a la persona de Cristo:

* es siempre necesaria una presencia humana y una acción historica para que se haga presente Dios,

- es en la vida humana donde se realiza el encuentro,

- pero no basta con una apreciación cualquiera de Jesús, sino la del Jesús que se encamina al Padre,

- el seguimiento supone una presencia y una convivencia del Jesús al que se sigue en el propio ser y en la propia vida, lo cual san Ignacio expresa en términos de estar con êl:

- no se trata de un puro modelo externo que se imila,

- sino de una vida que sigue, porque de algún modo ya está dentro de uno y que en la propia vida muestra la le que se tiene,

- el seguimiento está expresado en téminos de rechazo de este mundo y de oposición mutua con él:

- hay un primer paso de juicio y razón (Ejercicios Espirituales 96), que ya lleva consigo trabajo y pena (ibid. 95),

- pero se reclama como más esencial a la vida de Jesús y a su seguimiento la segunda etapa de su vida: la de su choque con el mundo que le lleva a la muerte.

+ Esto es lo esencial a la vida cristiana, de modo que la estructura sacramental es válida en cuanto viene-de y va-a este tipo real de cristianismo:

- en los Ejercicios de san Ignacio lo más llamativo y esencial es lo que se hace en la vida y el testimonio cristiano que ella da: 
* no debe olvidarse el escándalo histórico y la persecución eclesial que le causaron los Ejercicios a san Ignacio,

* no se trata de una pura celebración mistérica y cultual de la muerte y resurrección, sino de una vida real que es muerte y resurrección,

- el carácter "sobrenalural" se prueba en términos de seguimiento, lo cual si es comprobable y mucho más ajeno a engafios:

* la disputa del naturalismo-sobrenaturalismo se sitúa mejor en el campo de la realización histórica,

- el traslado del cristianismo al ámbito de lo sacramental puede ser la gran evasión religiosista que elude el compromiso cristiano,

- todo el resto de elementos "religiosos" estón referidos a este seguimiento y cobran de él su valor y su medida; entre ellos no hay contradicción, pero si subordinación hasta que llegue la identificación plena de la resurrección.

4.2. El carácter público (político) del seguimiento del pueblo de Dios en la realización del reino de Dios

- El seguimiento del Jesús histórico como superación del religiosismo y del secularismo:

+ el religiosismo que ha de ser superado consiste en buscar la relación con Dios y la salvación al margen de la vida y al margen de la realidad mediadora que es la vida de Jesús,

+ el secularismo que ha de ser superado consiste en buscar la relación con Dios y la salvación a través de acciones puramente seculares unidas intencionalmente con la voluntad de Dios:

- hay un secularismo de derechas, disimulado por un barniz religiosista, que es una cruda mundanización del cristianismo, pues sustituye, de hecho, los valores cristianos por valores que son su olvido o su negación,

- hay un secularismo de izquierdas que no ve la necesidad de ningún "más" al sentido y a los medios de la acción historica, que usan los hombres comprometidos con el pueblo en el cambio de las estructuras de pecado:

- se trata, desde luego, de una acción incipientemente cristiana y, en ese sentido, no serí secularista,

- pero no es una acción plenamente cristiana, al menos en lo que el cristianismo tiene de anuncio más allá de la denuncia y de la 
liberación.

+ Jesús es plenamente secular y en su secularidad es la máxima realización del reino de Dios y la máxima presencia de Dios al hombre y del hombre a Dios:

- la secularidad de Jesús es manifiesta no sólo porque no pertenece a la casta religiosa, sino porque su predicación del reino de Dios se convierte espontáneamente en acción pública:

* aparece como hombre de Dios y en continuidad con la tradición del pueblo de Dios, pero ni se aparta del mundo (esenios) ni pertenece a las estructuras jerárquicas de la religión judía,

* su predicación y su acción, porque son del reino de Dios, ponen en conmoción a los poderes públicos, que reaccionan políticamenLe contra él,

- es en esta forma de vida histórica donde él mismo encuentra y donde anuncia el reino de Dios.

+ Jesús no funda directamente una religión institucionalizada, sino que, ante lodo, busca a seguidores, que en su seguimiento prosigan su misión:

- en la teologia de san Marcos inmediatamente después del primer anuncio, llama al seguimiento y al seguimiento apostólico a los cuatro primeros discipulos (Mc 1, 14-20); y en la última etapa de su vida plantea las condiciones negacionales del seguimiento (Mc 8, 34-38),

- los seguidores de Jesús constituyen el pueblo de Dios, que personalmente y como pueblo deben seguir históricamente lo que fue la vida del Jesús historico:

- se trata de un seguir que es un proseguir.

- Loda institucionalización posterior debe someterse a este criterio fundamental y mensurarse por êl.

- Los seguidores del Jesús histórico, como pueblo de Dios, en el seguimiento histórico, preparan la llegada definitiva del reino de Dios:

+ No se trata de una pura imitación ahistórica, sino de un proseguimiento historico:

- el principio de esta historización progresiva es fundamentalmente el espiritu de Cristo que anima a los que le siguen.

- con los criterios fundamentales del Jesís historico hay que enfrentarse históricamente a la propia situación histórica en la que debe anunciarse el reino: 
* Jesús anunció el reino de Dios, pero en una situación histórica, que le respondió históricamente, de modo que el seguimiento personal de sus seguidores se realizó en esa situación histórica,

* pero la salvación que debemos anunciar no se inventa, sino que, fundamentalmente, está dada y por eso se trata de un estricto seguimiento: es un pro-seguir.

+ Los seguidores lo que siguen anunciando y haciendo es la presencia del reino entre los hombres:

- los dos términos deben mantener su plena vigencia se anuncia el reino, pero se lo anuncia históricamente a los hombres:

* el que no tenga fe en la eficacia salvífica del reino no debe entenderse a sí mismo como seguidor de Jesús,

* pero el que no pueda mostrar el carácter histórico de esta salvación y sufrir las consecuencias en la persecución, tampoco puede entenderse a sí mismo como seguidor de Jesús,

$\checkmark$ hay un criterio cristiano de la historicidad del seguimiento que es el padecer las mismas persecuciones históricas que sufrió el Jesús histórico y sus primeros seguidores:

* siempre se ha viswo en una cierta cruz la prueba del auténtico cristianismo; lo que ahora se ve más claro es que esta cruz debe ser histórica y no puramente interior $e$ individualista,

- la persecución no viene por el puro anuncio, sino por el forzoso carácter histórico de ese anuncio, que cobra un túpico carácter de denuncia y de lucha cuando choca contra el poder del pecado.

+ El carácter abierto y dirigido del seguimiento hace que se conviera en una tarea, cuya concreción histórica debe lograrse cada vez, sin que esto leve consigo necesariamente formas de relativismo:

- es necesaria una discreción de esplritus histórica,

$\checkmark$ pero los principios orientadores de esta discreción ya están dados.

5. La antinomia del seguimiento de Jesús y de la realización del mundo en la meditación de las dos banderas

\subsection{El enfrentamiento de dos modos de entender la salvación del mundo}

- En el momento de la elección del modo de vida aparecen dos posibilidades fundamentales contrarias, sobre cuyo valor cristiano hay que ponerse muy en claro para no errar. 
+ tal como las presenta san Ignacio no cabe opción desde un punto de vista cristiano, pero es porque ha puesto con todo relieve y explicitud ha desenmascarado- algo que sí puede pasar por cristiano:

- es algo que san Ignacio propone, por un lado, de Cristo y, por otro, de Lucifer, de modo que no se trata de mayor o menor perfección cristiana, sino de algo cristiano y de algo anticristiano,

- pero a pesar de ser anticristiano, necesita de un estricto desenmascaramiento, pues de lo contrario podría pasar por cristiano,

+ de hecho, se trala de dos posibilidades no sólo contrarias entre sí, sino que están en constante pugna no directamente entre sí, sino a través de la historia del hombre:

- son dos interprelaciones de la existencia humana, que pretenden imponerse como interpretaciones de lo que es religiosamente - Cristo y Lucifer - la historia humana y su plenitud salvífica,

- plantean una humanidad dividida tanto en cada hombre como en el conjunto de los hombres, según sigan como noma una u otra de las interpretaciones:

- se trata de reunir a muchos debajo de la misma bandera,

* estos muchos están enfrentados en ejércitos distintos, lo cual hace ver la forzosidad de la lucha entre quienes llevan a la misma historia una u otra bandera.

- Lo que caracteriza fundamentalmente una postura anticristiana está formulado por san Ignacio en tres términos fundamentales con un orden preciso: riqueza, honor, soberbia, tras lo cual vienen todos los demás vicios (Ejercicios Espirituales, 142):

+ que el planteamiento ignaciano sea aquf plenamente en términos del Jesús histórico y no en térninos religiosistas y menos triunfalistas, parece claro:

- en la vida de Jesús, los que de verdad se le opusieron, porque se sintieron sacudidos, fueron los ricos, los poderosos, los que gustaban los honores, etc.,

0 no se interpretan estos tres elementos unidos tanto como pecados, sino como principios de pecado, como formas estructurantes de vida:

- dada la biograffa de san Ignacio y los catálogos normales de pecados, podría esperarse un planteamiento muy distinto,

- los tres escalones son principios históricos, configuradores de la sociedad tanto como de los individuos. 
+ Riqueza, honores, soberbia son la expresión objetiva de la dominación e incluso determinan la estructura de esa dominación:

- apoyado en el ejemplo de Jesís y en su experiencia propia (como suele, ut in pluribus, Ejercicios Espirituales, 142), se propone a las riquezas desde su carácter de codicia o acumulacion, como principio del desorden:

- san Ignacio lo propone fundamentalmente en términos individuales y no se da cuenta explícita de lo que es este mismo problema a niveles sociales y nacionales,

- pero el principio "malerialista" de la riqueza como configurador de la vida está claramente explicitado en él,

- asimismo, el honor, apoyado en el tener más, como ideal que se busca alcanzar, es principio de alienación.

- sería la soberbia la formulación más explícila de la dominación, en cuanto implica que todos los demás queden sometidos al que está al frente de la estimación social por la riqueza que posee:

- el esquema es aś también individual, pero es totalmente válido para estructuras sociales de la magnitud que sean,

- se trata, en definitiva, de una interpretación teologica que abarca a todo el mundo de los hombres.

+ La penetración diabólica es objetiva y es universal, de modo que es fácilmente reconocible a pesar de su caracter teologal:

- "considerar cómo hace llamarniento de innumerables demonios y como los esparce a los unos en tal ciudad y a los otros en otra, y así por todo el mundo, no dexando provincias, lugares, estados ni personas algunas en particular" (Ejercicios Espirituales, 141):

- no sólo las personas, sino las provincias y los lugares tienen sus demonios propios,

- lo cual significa o que el lugar como tal es capaz de demonización o que el demonio particular actúa distinlamente, según el lugar, lo cual es equivalente a lo anterior,

- quedan asi objetivados no ś́lo los pecados, sino también los poderes del pecado y los agentes del pecado, todo lo cual constituye una estructura objetiva que se opone a la estructura objetiva que supone el campamento del reino de Dios:

* La lucha, siendo teologal, se convierte asi en histórica,

- la lucha, siendo histórica y sin dejar de serlo en ningún momento, 
se convierte en teologal, precisamente por las objetivaciones del pecado que propone el evangelio y que san Ignacio recoge magistralmente.

+ En definitiva, lo que se nos expone aquil es la teología sinoptica de las tentaciones de Jesús (cf. I. Ellacuría, Teología polfitica, San Salvador, 1973, pp. 29-32):

0 las piedras en pan, el triunfo en el templo y la dominación de las naciones, responden a la riqueza, al honor y a la soberbia,

- tienen el mismo carácter mesiánico y público, además de ser personales:

- se confunde el carácter de tentación religiosa y de tentación política,

- es una verdadera tentación cristiana y no algo que desde un principio aparece como absolutamente contrario a la visión cristiana.

- Lo que caracteriza fundamentalmente la postura cristiana está formulado también en tres términos fundamentales con su orden propio: pobreza, oprobio, $y$ humildad:

+ La estructura de la presentación de la bandera de Cristo es simétricamente contraria a la de Satón, por lo que deben hacerse las mismas consideraciones sólo que con signo contrario:

$\checkmark$ pobreza, oprobios, humildad son expresión del servicio y definen la estructura de la liberación cristiana,

- la penetración de estas fuerzas del bien debe ser también objetiva y universal,

0 expresan objetivamente las respuestas de Jesús a las tentaciones del desierto.

+ La razón de la preferencia por esta nueva estructura de valores no es otra que la del seguimiento de Jesús y no ninguna deducción racional:

- se da por supuesto el cumplimiento de las obligaciones formuladas en la ley (primera y segunda manera de humildad).

- pero lo específicamente cristiano está en la tercera manera de humildad: "por imitar y parescer más actualmente a Christo nuestro Sefior, quiero y elijo más pobreza con Christo pobre que riqueza, opprobrios con Christo lleno dellos que honores, y desear más de ser estimado por vano y loco por Christo que primero fue tenido por tal, que por sabio ni prudente en este mundo" (Ejercicios Espirituales, 167): 
* la razón de este comportamiento es el valor absoluto que se da al ejemplo histórico de Cristo.

* lo que se propone, consiguientemente, no es un comportamiento cĺnico, sino aquel tipo de comportamiento y por aquellas razones que fueron lo propio del Jesús histórico:

- la locura de Jesús y sus afrentas resultan del contraste entre su visión desde Dios y la visión del mundo.

- se trata, por tanto, de una locura histórica frente a un mundo histórico, cuyos valores son los de la primera bandera.

+ Este comportamiento de Jesús y de sus seguidores pone en conmoción a las personas, pero también y sobre lodo a las estructuras socio-políticas:

- se trata, en definitiva, de la subversión de los valores fundamentales, de las culturas mundanas, de las culturas endemoniadas, y esto no puede llevar más que a la lucha y a la contradicción,

- se trata, también, de despertar dinamismos que estructuren un mundo nuevo con hombres nuevos regidos por una escala de valores bien definida.

5.2. El caŕ́cter aparentemente paradojico de la realización del mundo frente al modelo de la salvación cristiana

- El dinamismo histórico de la construcción del mundo esta, de hecho, basado en los valores de la primera bandera:

+ las grandes civilizaciones dominantes, las clases sociales dominantes y los individuos dominantes se apoyan en el dinamismo de la riqueza, el honor y el poder de dominación,

+ los pueblos, clases e individuos que obligadamente viven la pobreza, la humillación y la dominación, son los pueblos atrasados.

- Pero aun la pura visión histórica muestra que esos valores realizan un mundo que es la configuración misma del pecado y del mal:

+ un mundo que permite y aun obliga a que la mayor parte del mundo quede fuera de sí es, en sl mismo, su propia condenación:

- si la condición hislórica de la riqueza, el honor y la dominación de unos pocos es la pobreza, el desprecio y la humillación de los más, estamos ante un máximo de irracionalidad y de destrucción,

- la mutua alienación -el falso fuera de sl- a que se someten los dos grupos en lucha, objetiva el profundo fracaso de un mundo montado sobre ese dinamismo. 
+ También aqư la visión histórica y la visión cristiana coinciden, al menos en la denuncia de la situación.

- La visión cristiana es fundamentalmente ulópica, pero no por ello deja de ser historica y operativa:

+ Lanto en la interpretación de la primera como de la segunda bandera deja de lado los mecanismos reales y se enfrenta directamente con la significación última de los valores,

+ es también utópica porque proyecta hacia constantes futuros de modo que ninguna realización histórica le puede resultar totalmente satisfactoria,

+ pero tiene un criterio de operatividad histórica e incluso medios (fundamentalmente proféticos) de operatividad, en la lucha contra aquellos valores que dan el sentido verdadero al sistema y en la lucha a favor de los valores contrarios.

6. El tercer mundo como lugar cristiano de la superación de la antinomia mundo-seguimiento del Jesús histórico

6.1. El tercer mundo como redescubrimiento de la necesidad de los valores cristianos y del significado histórico del seguimiento de Jesús

- Significado teologal del tercer mundo:

+ entendemos aqui por tercer mundo no un concepto estrictamente político, sino un concepto teológico:

- el concepto teológico de tercer mundo no es independiente del concepto histórico-político de tercer mundo, pero tampoco se confunde con êl:

* no es independiente porque es la concreción de la historia la que ofrece la mediación de Dios:

$\approx$ hay el peligro de entender el tercer mundo en términos puramente espiritualistas, que suponen una evasión de la realidad y de la responsabilidad históricas,

= la ambigiledad del tercer mundo no es excusa para rechazar su especial significación en la historia de la salvación,

* no se confunde porque el tercer mundo es una realidad historicamente ambigua, al menos en cuanto es producto de los otros dos mundos:

* el tercer mundo como denominación política abarca demasiadas diferencias y complejidades como para tomarlo como una realidad unitaria, 
- el tercer mundo tiene introyectado por muy distintas vas condicionamientos que también son objetivación del pecado e impiden su auténtica realización,

- cono concepto teológico el tercer mundo debe entenderse como el mundo de los pobres, en especial aquel mundo de los pobres que vive en la gran masa de las naciones oprimidas:

- no considera tanto a cada uno de los pobres en particular, sino el significado de un "mundo" de los pobres, lo cual supera reducciones empiricas, aunque corre el peligro de convertirse en algo deshumanizado y despersonalizado:

* es importante que no se convierta en una categoría puramente sociológica, sino que debe verse como una realidad con la que hay que ponerse en contacto, sobre todo en forma de praxis histórica,

- pero tampoco es una categoría puramente empfrica sino algo que debe transcenderse desde su profundo significado real y desde una apreciación teológica,

" ese "mundo" es, además, el de nuestra actual historia universal, que es la que da la realidad concreta de los fenómenos intranacionales:

- sitía el problema en un esquema de dominación activa que implica la necesidad de una respuesta activa en térninos de liberación,

* valora cada "mundo" particular de oprimidos dentro de la estructura universal de la opresión,

- ve ese tercer mundo como resultado del pecado y como víctima de él, pero también como lugar del escondimiento de Dios:

- al verlo desde el pecado sitúa su realidad en una estricta historia de la salvación,

- al verlo como lugar de predilección escandalosa de Dios ofrece la clave salvadora de la historia.

- El tercer mundo como siervo de Yahvé y como profeta universal:

+ el tercer mundo en cuanto es resultado por comisión y por omisión de los pecados del resto de la humanidad tiene características de siervo de Yahvé:

- no se sostiene sin más que el tercer mundo sea una corporización colectiva del siervo de Yahve: 
* esto plantearía, por lo pronto, dificullades hermenéuticas, que requiririan bastantes precisiones,

- plantearía también dificultades histórico-políticas en cuanto forzaría, a primera vista, a comportamientos demasiado pasivos y pacifistas,

- pero sí tiene un carácter claro de víctima en la que esłá especialmente presente Dios mismo:

* el doliente salva al que a él se acerca con deseo de curarlo (parábola del samaritano),

- el no posidente descubre lo que es el hombre y lo que debe ser, cuando no confia en las riquezas que tiene:

- Dios presente como salvador de los pobres y en los pobres de todos los demás.

+ El tercer mundo es en sí mismo una denuncia profética que descubre el pecado del mundo:

0 en un primer momento no es oprimido por ser profeta (caso del Jesús histórico), pero sí es pasivo resultado de un mundo movido por valores anticristianos:

- una sociedad que posibilita el tercer mundo con su carácter de mayoría universal oprimida se descubre a si misma como sociedad alienada, injusta e inhumana,

* aun en este carfcter pasivo de desvelación de la realidad verdadera de la sociedad mundial y de los hombres que viven en esa sociedad, es la negación del mundo historico montado sobre los valores de la primera bandera:

* la valoración suprema del lucro es una de las bases fundamentales de esta configuración injusta,

- la valoración de la dominación como forma usual de coexistencia es el ejercicio mismo de la opresión.

- la negación del amor y del servicio es la causa de dolores sin fin.

- Ia concentración en puras leyes técnicas de desarrollo es la anulación de la realidad humana,

- en nuestro actual momento histórico, el tercer mundo deberfa tomar parte activa en la lucha profética de liberación:

- en el Antiguo Testamento hay una larga tradición profetica en que 
el castigo de Dios por los pecados del mundo se visibiliza en intervenciones armadas, cuyo fin es frecuentemente la salvación del castigado,

- en las cuestiones historicas la denuncia de la palabra puede y debe ser acompantada por la denuncia de la acción, aunque la determinación de esta acción profética tenga sus criterios propios, que no sin más son los de una acción política,

- deberia ser también un anuncio viviente de los valores cristianos como ideal de la realización del mundo:

* son los valores anticristianos los que lo han siuado en opresión y en permanente destrucción propia,

- son los valores cristianos los que pueden animar la construcción de un hombre nuevo y de una sociedad nueva:

- en un proceso de liberación tiene que luchar contra todo aquello que impide la verdadera libertad,

- en un proceso de lucha tiene que anunciar el valor sagrado de la justicia,

- en un proceso de entrega tiene que mostrar las posibilidades redentoras del amor,

- en un proceso de desalienación tiene que mostrar las posibilidades humanizadoras de una vida de desprendimiento que busca la salvación de Dios no en las cosas que se quitan, sino en lo que no se puede arrebatar.

6.2. El tercer mundo exige y ofrece condiciones óplimas para encarnar históricamente la exigencio cristiana

- En el tercer mundo tienden a confluir la dinámica de lo secular y de to cristiano:

+ en el tercer mundo se unifican singularmente la exigencia de una concreta acción secular de liberación y de una acción cristiana de liberación:

- esa acción secular no puede ser la de un desarrollismo, pues ha sido éste históricamente el causante de la situación y estra, además, fundado sobre valores no cristianos,

0 en la línea de la liberación hay una singular confluencia:

- denuncia de estructuras y personas injustas, previa una encarnación con el proyecto histórico de los pobres, 
* construcción de las nuevas posibilidades de humanización a partir de la propia situación histórica,

* construcción de un hombre nuevo en una tierra nueva, que sean mediación de la presencia salvifica de Dios.

+ La liberación redentora no es una acción puramente secular, sino estrictamente cristiana:

- la acción puramente secular lleva a parcializar la tarea o a abandonarla o a utilizar medios deshumanizadores,

- la acción liberadora cristiana va buscando en el proceso historico la presencia del reino de Dios tal como lo anunció el Jesús histórico:

* una vuelta al mundo de los pobres por amor es de por sí una vuelta al evangelio y al modo cristiano de la salvación.

* un seguimiento histórico de Jesús no es posible sin una incorporación de su espíritu:

* encarna lo que es en Jesús la visibilización del Padre,

- necesita de una fe, una esperanza y un amor, que realizados en la historia, se proyectan más allá de ella

- El tercer mundo supone un desafio decisivo para la potenciación del cristianismo en una vuelta a los valores evangélicos, con lo cual se acrecentará su credibilidad:

+ ha sido en el contacto con el poder y con la riqueza donde la Iglesia ha mundanizado sus formas:

- la Iglesia más aparente ha sido desde siglos Iglesia de la cultura occidental, de la cultura de los opresores y dominadores del mundo,

- esto le ha dado una especial estructura visible y le ha restado credibilidad cristiana.

+ En la vuelta al mundo de los pobres vuelve como a su lugar natural, al lugar en que la quiso el Jesuis histórico:

- no es una vuelta puramente pasiva, que menospreciara la necesidad de esperanza activa y de lucha que exigen la situación de la mayoria de la humanidad, lo cual no satisfaria a la realidad histricica,

- es una vuelta activa, como fue la de Jesús en su vida pública:

- La Iglesia debe ejercer una acción y un poder en la misma línea de la acción y del poder de Jesús, 
* la Iglesia debe tener fe en sus posibilidades de salvación de este mundo y en ese sentido propiciar realmente el encuentro y la realización de una nueva elapa histórica.

+ En esta lucha le espera la persecución como respuesta de las estructuras opresoras, pero debe tener esperanza en el futuro de la historia:

- es su propio signo histórico y responde a la muerte no buscada, sino encontrada por Jesús,

- pero está movida por la esperanza de la resurrección.

7. El esquema muerte-resurrección como interpretación y praxis de nuestro proceso histórico y de nuestro camino personal

7.1. El esquema muerte-resurrección en la dinámica interpretativa de los Ejercicios de san Ignacio

- La disposición de la tercera y la cuarta semana seffalan el carácter histórico de la muerte y la resurrección:

+ el carácter histórico estriba, por lo pronto, en que es por la muerte y una muerte histórico-política, por donde se llega a la gloria de la resurrección,

+ el cristiano debe seguir el mismo camino de la muerte para llegar a la misma gloria de la resurrección:

- no hay paso a la resurrección, sino por la muerte, y en concreto, no hay paso a la resureoción histórica, sino por la muerte histórica,

- en la muerte histórica y en la resurrección histórica se prenuncian y se posibilitan la muerte y la resurrección escatológicas.

- Elementos historicos del seguimiento en la muerte, según la Tercera semana:

+ san Ignacio insiste en el carácter histórico y no meramente místico o sobrenatural de la pasión de Cristo e insiste asimismo en la reproducción histórica y no meramente mística o cultual de esa pasión:

- "el primer preámbulo es traer la historia" (Ejercicios Espirituales, 191); "el segundo, composición viendo el lugar" (Ejercicios Espirituales, 192); con eso, "ver las personas" (Ejercicios Esírituales, 194); "oir lo que hablan", "mirar lo que hacen" (ibid.); "considerar to que Christo nuestro Seflor padesce en la humanidad" (Ejercicios Espiriwales 195); "considerar cómo la Divinidad se esconde" (Ejercicios Espirituales, 190): 
- el "misterio" de la pasión está aquí lotalmente historizado, aunque en san Ignacio no se resalte el por qué de esta determinada historización,

- el reconocimiento del valor absoluto del ejemplo historico de Jesús es manifiesto y no debe entenderse en términos puramente psicológicos,

- "demandar lo que quiero: será aqul dolor, sentimiento y confussion, porque por mis pecados va el Sefior a la passión" (Ejercicios Espirituales, 193); "comenzar con mucha fuerza y esforzarme a doler, tristar y llorar" (Ejercicios Espirituales, 195); "qué debo yo hacer y padescer por él” (Ejercicios Espirituales, 97):

* san Ignacio quiere que se reproduzcan en el ejercitante sentimientos de identificación con el Jesús histórico.

- la mediación que emplea para esa identificación es la de que mis pecados llevan al Sefior a la pasión,

- no insiste muy explícitamente en que es la lucha contra el pecado la que llevó a Jesús a la pasión, y en que es esa misma lucha la que origina realmente la pasión del cristiano:

- la identificación puramente de sentimientos sería un psicologismo que no llegarfa a la profundidad del seguimiento.

* en san Ignacio se supera ese psicologismo como lo demuestra Loda su espiritualidad y aun la explícita referencia que hace aqur a lo fundamental de la Segunda semana (Ejercicios Espirituales, 199).

- san Ignacio pretende que este momento de pasión conserve toda su fuerza y no quede anulado por elementos que perturbarian su historicidad:

* "no procurando de traer pensamientos alegres, aunque buenos y sancios, asi como son de resurrección y de gloria, mas antes induciendo a mi mismo a dolor y a pena y quebranto, trayendo en memoria frequjente los trabajos, fatigas y dolores de Christo nuestro Sefior, que paso desde el puncto que nasció hasta el misterio de la passión en que al presente me hallo" (Ejercicios Espirituales, 206):

* aquí se presenta la pasión no como un acontecimiento último, sino como algo que ocupa toda la vida de Jesús,

- la identificación afectiva, aquí propuesta, dice relación esencial a una vida realmente identificada en el seguimiento, pues 
tampoco bastan las obras externas, si no hay esa identificación interior,

- no se puede prescindir de este elemento de pasión; san Ignacio es fiel al pensamiento teológico de que aún falta por cumplirse la pasión de Cristo.

- Elementos históricos del seguimiento en la resurrección, según la Cuarta semana:

+ Es también un elemento básico de la interpretación teológica de san Ignacio la presencia en la propia vida de la resurrección:

- para ver lo que es la resurrección, san Ignacio acude predominantemente a los hechos históricos y no a interpretaciones mistéricas,

- los mismos elementos históricos y el mismo proceso de identificación historica que propone en la Tercera semana son los propuestos en la cuarta, de tal modo que la estructura formal de las meditaciones es la misma

+ San Ignacio quiere que sean operantes en la propia vida los elementos úpicos de la resurrección:

- no piensa que ya han pasado las otras etapas y que uno debe vivir como si el hombre y la historia estuvieran ya en la etapa del triunfo definitivo y de la resurrección,

- pero si piensa que tanto afectiva como efectivamente la resurrección debe hacerse presente en la historia:

- el cristianismo no es pura negatividad, sino que esta negatividad debe ir inundada de positividad,

- el cristianismo es también fiesta porque Dios salvador ya está entre los hombres.

7.2. El esquems muerte-resurrección como principio de la acción personal y de la prexis histórica en la historia de la salvación

- Muerte en cruz y resurrección como tipificación del seguimiento del Jesús historico:

+ La cruz descubre y quita el pecado del mundo como lo muestra la resurrección:

- hace ver que hay pecado y lo interpreta como negación de Dios en la negación del hombre y negación del hombre en la negación de Dios:

* en Jesús es negado el Hijo como camino hacia el Padre, 
* Jesús es negado por su negación del mundo, por su lucha contra los poderes históricos del mundo,

- quita por la muerte el pecado del mundo:

- la salvación, supuesto el pecado, no puede ser sino salvación redentora, pues no se quita una ofensa, sino que se supera un mal,

- sólo por la redención hasta la efusión de sangre hay salvación:

- no hay paso a la resurrección del hombre nuevo, sino por la muerte del hombre viejo,

- esto no prejuzga cuóles son los medios personales e históricos de redención, sino lan sólo los sitúa a la luz del Jesús histórico.

+ La negación cristiana es positiva porque es negación de la negación:

- fundamentalmente es una negación del pecado, que es como tal una negación del hombre y de Dios,

- el Jesús histórico hace especial hincapié en esta necesidad no de la abnegación, sino de la negación:

* los texios situados en Marcos y Mateo despues de la reprensión de Pedro, muestran la importancia que tienen y muestran su esencia cristiana, pues están repetidos casi literalmente ( $c f$. Mc 8, 34-9,1; Mt 16, 24-28; Lc 9, 23-27; Jn 12, 25-26),

* el seguimiento de Jesús hasta tomar su cruz (significado técnico) está en el contexto de la negación que el mundo hace de Jesús, en cuanto éste es negador del mundo,

- es la pasión por la vida verdadera, es la pasión por Dios o por el reino de Dios, la que obliga a esta negación:

* dominados por el poder del pecado e identificados con él, no hay más camino que la negación en la conversión, el arrepentimiento, porque el reino está cerca,

- si el mundo al que vamos en misión está dominado por el pecado, es el anuncio de la vida lo que lleva a la denuncia,

- la forma positiva de la negación es la donación total a Dios en los demás hombres:

- el vaciamiento de si mismo como vaciamiento del pecado en todas sus formas de egoísmo,

- el vaciamiento de sl mismo por el hecho de que ya no vivo yo, sino que Cristo vive en mí, 
- el ser para los otros, especialmente para los oprimidos como forma de la filiación divina en su manifestación a los hombres y en su encuentro del Padre.

- El carácter político de la muerte de Jesús exige el carácter político de su resurrección:

+ históricamente, Jesús fue ajusticiado por razones políticas, y, teológicamente, murio por nuestros pecados:

- estas dos afirmaciones en vez de excluirse explican concretamente el modo histórico de la redención teologal,

- el comportamiento cristiano, como seguimiento del Jesús histórico, lleva forzosamente a formas continuas de muerte:

- el poder del pecado domina la configuración del mundo histórico y tiene que chocar con el poder de Cristo que busca la configuración del mundo desde la gracia,

- el estar activamente con los oprimidos pone forzosamente al profeta cristiano en litigio permanente con los opresores,

- la peligrosidad es asi criterio de la autenticidad de la fe y de la promesa de la resurtección:

- el anuncio de la negación del mundo tiene que ser peligroso.

- la ausencia de peligrosidad es criterio de que no se está en oposición con el mundo.

+ Si la muerte de Jesús tiene un carácter político, la negación de su muerte que es la resurrección tendrá que tener también un carácter político:

- lo contrario sería afirmar que el carácter histórico de la muerte de Jesús fue puramente ocasional y fortuito.

- el espíritu nuevo de la pascua es la puesta en marcha definitiva del hombre nuevo en la tierra nueva, pero en una historia de hombres viejos y de tierra dominada por el pecado,

- la presencia viva del Cristo resucitado es en forma distinta la presencia del mismo Jesús histórico.

\section{La contemplación en la acción del seguimiento}

\subsection{La desaparición del Jesús histórico en la Contemplación para alcanzar anor}

- La Comemplación para alcanzar amor tiene ciertas caracteristicas semejantes al Principio y fundamento y puede correr los mismos peligros de in- 
terpretación (cf. apartado 2):

+ aparentemente no aparece para nada el Jesús histórico, ni siquiera de modo explícilo el Cristo de la fe,

+ puede dar paso a un acceso a Dios ya no racional, sino más contemplativo y místico:

- desaparecen los modos típicamente cristianos, tal como se han propuesto en las partes anteriores de los Ejercicios,

- hay, sin embargo, una clara superación del Principio y fundamento en cuanto que el amor y un amor activo se constituye en la culminación de la relación con Dios.

- Pero la desaparición no puede ser sino aparente, pues de lo contrario los Ejercicios de san Ignacio se anularían a si mismos y, sobre todo, dejarian de ser cristianos:

+ la contemplación para alcanzar amor muestra, desde el punto de vista de la fe, la posibilidad real del encuentro de Dios en la creación y la posibilidad de recuperación de la creación como presencia de Dios:

- a pesar de que hay pecado en el mundo, el mundo sigue siendo lugar de presencia de Dios:

* el elemento moral y jurídico de la ofensa, que lleva a la interpretación de la redención por falsos caminos, es sustituido por el elemento de mal y destrucción real de Dios en la humanidad de Jesús y de los demás hombres,

* el mal del mundo, aunque desfigura el lugar de la mediación, no lo anula, con lo cual queda abierta la tarea de recuperar el mundo como mediación de Dios,

- la resurrección de Cristo es el anuncio del triunfo sobre el pecado y de la reconciliación de woda la creación entre sí y con Dios:

* en este momento del proceso que vive la resurrección historicamente, la relación con el mundo y con Dios es fundamentalmente una relación de amor,

* aquf está el fundamento cristiano de la reconstrucción del mundo como casa de Dios y casa del hombre, reconstrucción que no olvida ni la clave del Jesús historico ni el sentido político de la historia.

+ El amor del que habla san Ignacio es un amor como el que vivió el Jesús histórico: 
- es un amor que se debe poner más en las obras que en las palabras (Ejercicios Espirituales, 230):

* queda superado el momento engañoso de la palabra y, en general, los momentos "idealistas" e interioristas,

* queda superado el momento de la ortodoxia en la verdad de la ortopraxis, porque el amor cristiano es amor operativo y no puramente contemplativo,

- es un amor que consiste en comunicación: "en dar y comunicar el amante al amado lo que tiene o de lo que tiene o puede, y así, por el contrario, el amado al amante" (Ejercicios Espirituales, 231):

* la comunicación de bienes es la forma típica del amor de Dios al hombre, del hombre a Dios y de los hombres entre sf,

* la culminación de este amor está en dar la vida, porque nadie ama más que el que da su vida.

- Las formas de comunicación en el amor de Dios con los hombres y de los hombres con Dios:

+ hay una serie de momentos formalmente activos por parte de Dios que exigen por parte del hombre la continuación de su obra:

- "considerar cómo Dios trabaja y labora por mí en todas las cosas criadas sobre la haz de la tierra, id est, habet se ad modum laborantis. Asl como en los cielos, elementos, plantas, frutos, ganados, etc." (Ejercicios Espirituales, 236):

* hay aquí una obra de Dios, un trabajo de Dios, que incita a proseguir esa misma obra divina en el desarrollo de la naturaleza,

* el problema es si se desarrolla desde el pecado y para el pecado:

- el pecado estaría aquí en la negación del amor, en el desarrollo que no es comunicación,

- el pecado estaría en la dominación contrapuesta al servicio. como lo ha mostrado el Jesús historico,

- "traer a la memoria los beneficios recibidos de creación, redempción y dones particulares, ponderando con mucho afecto quánto ha hecho Dios nuestro Seffor por mi y quínto me ha dado de lo que tiene, y consequenter el mismo Seffor desea dárseme según su ordenación divina" (Ejercicios Espirituales, 234):

- aqui se trata formalmente de momentos históricos naturalizados y no como en el punto anterior de momentos naturales historizados, 
* Se trata también de un estricto hacer, pero de un hacer más inmediato, más libre y personal, con lo que de nuevo aparece lo histórico como lugar privilegiado de la presencia de Dios:

- estŕ el momento histórico de la acción y no puramente de la presencia quieta y aquietadora,

* está el momento histórico de la acción libre y personal,

- está el momento histórico del darse y comunicarse como forma típica de la acción cristiana, un darse que, en definitiva, es la donación de la persona misma.

+ Hay otros modos más estáticos de presencia, que representan en cierta forma la posibilidad de la acción y el resultado de ella:

- "mirar cómo Dios habita en las criauras, en los elementos dando ser, en las plantas vejetando, en los animales sensando, en los hombres dando entender; y así en mí dándome ser, animando, sensando, y haciéndome entender, asimismo haciendo templo de mí seyendo criado a la similitud y imagen de su divina majestad" (Ejercicios Espirituales, 235):

- hay una presencia divina en las cosas, la cual presencia es distinta según lo que sean las cosas:

- Dios se seculariza en las cosas,

- las cosas se sacralizan en Dios,

* el hombre es especialmente sagrado - templo- ya desde la creación por su carácter de similiud e imagen, to cual supone una concepción toológica bien avanzada,

- este carácter, a la vez sagrado y secular de todas las cosas y especialmente del hombre, es lo que permite y exige, además de posibilitar, la acción estrictamente cristiana en lo secular,

- "mirar cómo todos los bienes y dones descienden de arriba, asl como mi medida potencia de la summa y infinita de arriba, y asl justicia, bondad, piedad, misericordia, etc., asf como del sol descienden los rayos, de la fuente las aguas, etc." (Ejercicios Espirituales, 237):

- hay una contraposición lácita entre los bienes que vienen de arriba y los males que vienen de abajo, lo cual establece la lucha esencial de la creación y de la historia,

- cualesquiera bienes son de Dios, pero sólo en cuanto son concretamente bienes, es decir, hacen bien, de modo que el juicio sobre la bondad de algo $y$, consecuentemente, sobre la presencia de Dios, debe ser un juicio histórico. 
+ Por parte del hombre, el camino del encuentro con Dios es el mismo de la donación activa a través de acciones seculares e históricas:

- lo que se debe ofrecer fundamentalmente es la libertad, y lodo lo demás se puede ofrecer en cuanto por la libertad se puede poner al servicio de Dios:

- es la liberad - liberlad de y liberlad para- la que, en definiliva, establece la comunicación con Dios,

* donde la libertad no es posible, no es posible la comunicación personal con Dios,

- se trata de una contemplación de Dios en las cosas, que va a dar paso a la contemplación en la acción con las cosas:

- no hay acceso directo a Dios, sino que Dios es siempre para el hombre Dios-en, Dios-con, etc.,

* Dios se hace presente al hombre haciendo y el hombre hace presente a Dios y se hace presente a Dios haciendo:

- la contraposición de oración y acción es una contraposición abstracta o escapista,

- la oración es, en concreto, uno de los momentos de la acción, el momento de captación refleja en los modos cristianos de acción, lo cual no implica que no deba tener su tiempo adecuado.

8.2. La recuperación del Jesús histórico en el seguimiento de la acción histórica

- Hay una acción privilegiada para la comunicación y el encuentro de Dios y es la acción histórica del seguimiento del Jesús histórico, visto desde la fuerza de la resurrección:

+ es la acción histórica el verdadero "templo" de Dios, la casa de Dios y la morada del hombre:

- la acción histórica implica todas las demás formas de presencia, incluso las formas que podrlan parecer naturales y estáticas,

- pero anade las formas propias de la realización personal y, consiguientemente, las formas más propias del encuentro personal con Dios:

- el encuentro de persona a persona no se logra, sino en acciones personales,

- las acciones personales son formas totales de existencia humana. 
+ Dentro del marco de las acciones históricas, la acción histórica del encuentro por antonomasia de Dios, es la vida histórica de Jesús:

* Jesús encuentra a Dios y comunica a Dios en la vida que lleva,

* esta vida es donación plena de sí en el anuncio del reino en un determinado mundo socio-político.

+ Es, por tanto, en el seguimiento histórico de la vida historica de Jesús, donde se va a dar la verdadera contemplación cristiana en la acción.

- La acción que va a ser contemplativa y comunicativa del Dios cristiano es esa acción del seguimiento histórico:

+ Dios se hace presente en wdo, pero de un modo especial y úpicamente cristiano en el gemido de los oprimidos,

+ Dios se hace presente en toda acción buena, pero de un modo especial y t́picamente cristiano en la acción histórica que es liberadora del pecado, que oprime al mundo,

+ la liberación integralmente entendida sería, en nuestra situación, el lugar privilegiado de la acción que en su secularidad harla transparente la presencia y la acción del Dios salvador. 